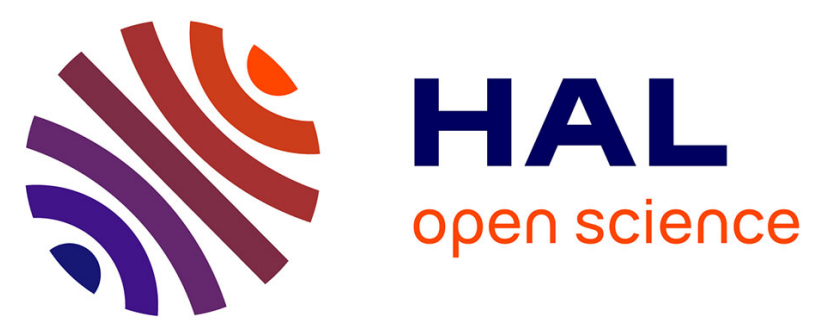

\title{
A Unique FPGA for the Implementation of Neural Strategies for Identifying Harmonic Distortions
}

Serge Raoul Naoussi Dzondé, Hervé Berviller, C.-H. Kom, Patrice Wira

\section{To cite this version:}

Serge Raoul Naoussi Dzondé, Hervé Berviller, C.-H. Kom, Patrice Wira. A Unique FPGA for the Implementation of Neural Strategies for Identifying Harmonic Distortions. Journal of Research in Electrical and Electronics Engineering, 2014, 3 (1), pp.1-7. hal-01020802

\section{HAL Id: hal-01020802 https://hal.science/hal-01020802}

Submitted on 22 Jul 2014

HAL is a multi-disciplinary open access archive for the deposit and dissemination of scientific research documents, whether they are published or not. The documents may come from teaching and research institutions in France or abroad, or from public or private research centers.
L'archive ouverte pluridisciplinaire HAL, est destinée au dépôt et à la diffusion de documents scientifiques de niveau recherche, publiés ou non, émanant des établissements d'enseignement et de recherche français ou étrangers, des laboratoires publics ou privés. 


\title{
A Unique FPGA for the Implementation of Neural Strategies for Identifying Harmonic Distortions
}

\author{
Serge Raoul Naoussi Dzondé ${ }^{(1)}$, Hervé Berviller ${ }^{(2)}$, Charles Hubert Kom ${ }^{(1)}$, Patrice Wira ${ }^{(3)}$ \\ (1) Laboratoire d'Electronique, Electrotechnique, Automatique et Télécommunication (L2EAT), \\ University of Douala, P.O. Box 8698, Douala, Cameroon \\ Email: dzonde@yahoo.com \\ ${ }^{(2)}$ Laboratoire des sciences de l'ingénieur, de l'informatique et de l'imagerie (ICUBE), \\ University of Strasbourg /CNRS - UMR 7163, \\ 23 rue du Lœss, 67037, Strasbourg, France \\ Email: herve.berviller@unistra.fr \\ (3) Laboratoire Modélisation, Intelligence, Processus, Système (MIPS), \\ Université de Haute Alsace, \\ 4 rue des Frères Lumière, 68093 Mulhouse, France \\ Email: patrice.wira@uha.fr
}

\begin{abstract}
In this paper, three optimized neural harmonics extraction methods are presented and compared in terms of simulation results, FPGA implementation and practical considerations. Those distortion identification schemes are used in nonlinear loads compensation with Active Power Filters (APF). This optimization is performed in order reduce the number of hardware resources required for digital implementations. The given approaches tend to use only one Adaline and remain powerful even under unbalanced conditions of voltage. In this way, the implementation of all the functionalities of the active filter control has been realized by means of a unique FPGA chip. Moreover, even the most consuming method (i.e., the ITM) uses less than $52 \%$ of hardware resources. Even though the $m p-q$ technique (based on the instantaneous reactive power theory) is not the fastest in terms of hardware response time, it stills appear the most powerful for its filtering aptitudes with an experimental sourceside current THD of $3.3 \%$ after compensation.
\end{abstract}

\section{INTRODUCTION}

I $\mathrm{n}$ order to reduce distortions created by non-linear loads (static rectifiers, adjustable speed drives, DC/AC converters, etc.), the Active Power Filter (APF) is nowadays one of the most powerful solutions. It is therefore used in a distribution power system to avoid serious inherent problems such as transformer overheating, machine vibration, motor failures, higher line losses, etc. The switching actions of power converters result in distorted input currents, which contain a fundamental and some other higher order harmonics. Injection of compensation currents in the electrical power supply by means of an APF allows sinusoidal current shape recovery as well as reactive power compensation. In the process of harmonic compensation, detection of load current harmonics is one part, while the generation of compensating harmonic currents by means of converter switching is the other part of APF. Performances of APFs depend on harmonic detection methods for generating current references, current control method, and dynamic characteristics of their power converter circuit. The filtering performances are essentially affected by the current references generation.
Most of the contributions for harmonics extraction were in time domain. For example, the Synchronous Reference Frame (SRF) theory is based on the filtering of DC current components by a low-pass filter in synchronously rotating frame [1]. At the beginning of the 1980s, Instantaneous Reactive Power Theory (IRPT) emerged and is still now one the most powerful technique for distortion identification in power systems. The objective of the IRPT was to find an effective control strategy to compensate three-phase nonlinear loads by means of an APF [2][3].

A lot of recent research work investigates and tries to improve APFs by developing new control laws. In this way, Artificial Neural Networks (ANNs) have been successfully applied in power systems like APF. Indeed, some ANNsbased harmonics detection schemes such as Improved ThreeMonophase (ITM) and the Modified SRF (MSRF) methods also called TPF for Two-Phase Flow have been discussed in [4][5] with interesting adaptive properties. Another way is an IRPT formulation based on a neural approach which works properly for phase and symmetrical components estimation in power systems perturbed by harmonics, random noise and source voltage sags [6][7]. In [8][9], authors discuss a multiplexing approach focused on the IRPT, and based on a single neural network, i.e., the Adaline. This was motivated by a need for simplicity and flexibility inherent to ANNsbased control strategies, but also to optimize the hardware resources required in digital implementations.

Implementing complex algorithms on reprogrammable devices allows fast time-to-market, enables easy prototyping through Hardware Description Language. Since ANNs in general are inherently parallel architectures, implementing ANNs on Field Programmable Gate Array (FPGA) seems to be an excellent choice due to its aptitudes for parallel processing [10][11][12].

The work presented in this paper gives a comparative study of three recent neural schemes for distortion identification in terms of settling time and filtering capability against load currents fluctuations and unbalanced conditions. These methods are also compared in terms of execution times and 
required resources area in case of FPGA implementation. In recent works, the APF control scheme is generally implemented in real time using a Digital Signal Processor (DSP) in a dSPACE board board. Sometimes this board is used in association with an FPGA card in which the current controller which drives the gating signals for the APF inverter is implemented. Another purpose of this work is to show that it is possible to implement all the functionalities of the APF control unit by means of a unique FPGA chip.

The harmonics identification methods are simulated in Matlab/Altera Dsp Builder ${ }^{\mathrm{TM}}$. In Section 2, neural methods for reference current generation are investigated and algorithms are introduced. Performances of the methods regarding simulation results and FPGA programming abilities are analyzed in Section 3. Finally, in Section 4, experimental results are presented to confirm those obtained after simulations, and on the other hand to show the feasibility of implementing the whole APF control unit in FPGA as the unique target.

\section{ANN-BASED MAJOR DISTORTION IDENTIFICATION APPROACHES}

In general, the APF control unit can be decomposed in the following blocks. A first block which has to identify all the present harmonic components and to separate the fundamental component from the other harmonic components which are converted in resulting reference currents. A second block uses these reference currents to re-inject them in realtime into the utility source with opposite phase though a power circuit, i.e. an inverter and an output filter, and a third block which preserves the DC-link voltage at its reference value. The reference currents are issued from an ANN which learning process is done on line. Fig. 1 presents a shunt APF in an electrical power grid. As it is one of the most important block of the APF control unit, this paper discusses three neural methods for generating the reference currents.

\section{A. IRPT based multiplexing approach}

The original reference currents generation architecture is made up of three identical ANNs. In [8][9], a simplified structure is proposed which uses only one ANN by a multiplexing technique. Fig. 2 shows the obtained structure which results in optimizing hardware resources consumption. The instantaneous powers $p$ and $q$ are calculated from the voltages and currents in $\alpha \beta$-frame with (1):

$$
\left[\begin{array}{l}
p \\
q
\end{array}\right]=\left[\begin{array}{cc}
v_{\alpha} & v_{\beta} \\
-v_{\beta} & v_{\alpha}
\end{array}\right]\left[\begin{array}{l}
i_{\alpha} \\
i_{\beta}
\end{array}\right]
$$

Let $z_{k}$ be at iteration $k$ one of the desired instantaneous powers to be learned by the ANN. After a training process, the neural network will estimate its value $\hat{z}_{k}$. The corresponding errors $e_{k}=z_{k}-\hat{z}_{k}$ should be stored in a memory. The learning serves to update the weight $w_{k j}$ of the neural structure for any input $x_{j}$ as illustrated by relation (2):

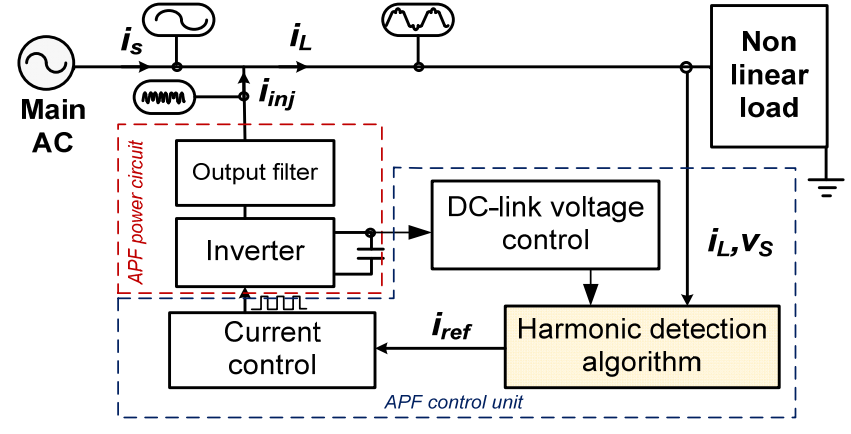

Fig. 1. A shunt APF in an electrical power system

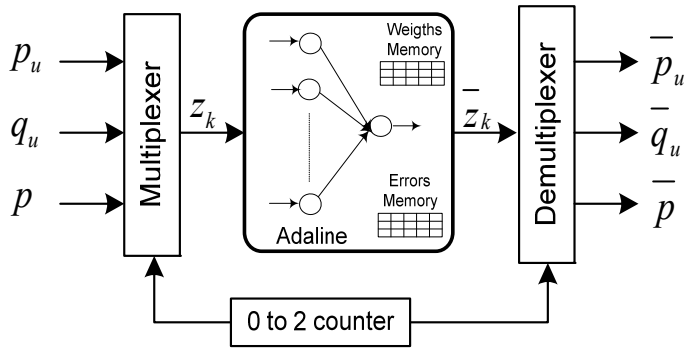

Fig. 2. Application of the multiplexing technique on the $p-q$ harmonics detection method.

$$
\mathbf{W}_{(k+3) j}=\mathbf{W}_{k j}+\frac{\mu \cdot e_{k} \cdot \mathbf{X}_{j}}{\lambda+\mathbf{X}_{j}^{T} \cdot \mathbf{X}_{j}} ; j=1, \ldots, N
$$

This learning process is based on the Widrow-Hoff algorithm where $\mu$ is the learning rate $(0<\mu<1), \lambda$ is an appropriate constant to ensure a non-zero denominator and $N$ the number of Adaline inputs.

Finally, the estimated DC component $\hat{z}_{k}$ of $z_{k}$ is obtained by using the first two elements of the weight vector $w_{k} \cdot p_{u}$ and $q_{u}$ are fictitious instantaneous powers obtained from the symmetrical component extraction block. On the other hand, a demultiplexer is used to separate the DC components $\bar{p}_{u}$, $\bar{q}_{u}$ and $\bar{p}$ respectively. AC values of $p$ and $q(\tilde{p}, \tilde{q})$ are produced with the harmonic components of the load current. The design is then simplified for area efficient implementation.

In order to compensate the harmonics and instantaneous reactive power, the compensating currents $i_{\text {ref } \alpha}$ and $i_{\text {ref } \beta}$ on $\alpha \beta$ coordinates are calculated by using $-\tilde{p}$ and $-q$ as given in (3):

$$
\left[\begin{array}{c}
i_{r e f \alpha} \\
i_{\text {ref } \beta}
\end{array}\right]=\frac{1}{\Delta}\left[\begin{array}{cc}
v_{\alpha} & -v_{\beta} \\
v_{\beta} & v_{\alpha}
\end{array}\right]\left[\begin{array}{c}
-\tilde{p}+p_{d c} \\
-q
\end{array}\right],
$$

$p_{d c}$ is the added power to achieve the capacitor voltage $v_{d c}$ regulation, at the $\mathrm{DC}$ side of the inverter. The reference compensating currents in the $a-b-c$ coordinates are then obtained with (4): 


$$
\left[\begin{array}{l}
i_{\text {refa }} \\
i_{\text {refb }} \\
i_{\text {refc }}
\end{array}\right]=\sqrt{\frac{2}{3}}\left[\begin{array}{ccc}
1 & -1 / 2 & -\frac{1}{2} \\
0 & \frac{\sqrt{3}}{2} & -\frac{\sqrt{3}}{2}
\end{array}\right]^{T}\left[\begin{array}{l}
i_{\text {ref } \alpha} \\
i_{\text {ref } \beta}
\end{array}\right]=T_{32}\left[\begin{array}{l}
i_{\text {ref } \alpha} \\
i_{\text {ref } \beta}
\end{array}\right] .
$$

where $\mathrm{T}_{32}$ is the Concordia matrix.

\section{B. ITM identification method}

As presented in [4][5], the three-monophase method works directly with the distorted current $\mathrm{iL}(\mathrm{t})$ and identifies fundamental component $i \operatorname{Lf}(\mathrm{t})$, and thus the harmonics $i \operatorname{Lh}(\mathrm{t})$ for each phase with two Adalines. By multiplying the load current by sin $\omega t$, we obtain the expression (3) which is then represented by one Adaline.

$$
\begin{aligned}
& { }_{L}(t) \sin \omega t=\frac{1}{2}\left(I_{12}-I_{12} \cos 2 \omega t+I_{11} \sin 2 \omega t\right) \\
& +\frac{1}{2} \sum_{n=2 \ldots n}\left(I_{n 2} \cos (n-1) \omega t-I_{n 2} \cos (n+1) \omega t\right) \\
& +\frac{1}{2} \sum_{n=2 \ldots n}\left(I_{n 1} \sin (n+1) \omega t-I_{n 1} \sin (n-1) \omega t\right)
\end{aligned}
$$

where $I_{12}$ is the bias weight of the corresponding Adaline. For the other Adaline, issue from the multiplication of $i_{L}(t)$ and $\cos \omega t, I_{11}$ is the bias weight. By looking more closely at equation (3), it can be noticed that besides the weight $I_{12}, I_{11}$ can also be determined as the steady state weight corresponding to the input $1 / 2 \sin 2 \omega t$ of the same Adaline. In this way, it is shown that the three-phase harmonics identification can be done with one Adaline per phase.

\section{MSRF method}

The other neural identification method, i.e. the MSRF [4][5] is based on the known SRF technique. This approach relies on an original decomposition of the three-phase currents. These currents are successively converted into the $\alpha \beta$ - and DQ-spaces with respectively the Concordia and Park transforms. In DQ-space the currents are decomposed in linear expressions, AC components are separated from the DC's by an Adaline. The AC components represent harmonic currents into the same space. By applying Concordia and Park transforms to those currents, we can finally obtain the threephase reference currents. With the proposed ANN-based it is then possible to obtain all the reference currents with only one Adaline.

\section{SIMULATION RESULTS AND FPGA IMPLEMENTATION}

Simulations have been made in various utility conditions using Simulink ${ }^{\mathrm{TM}}$ with Altera Dsp Builder ${ }^{\mathrm{TM}}$ toolbox for different controller configurations. Switching frequency of the inverter is set at $12.5 \mathrm{kHz}$. Neural reference currents generation associated to a three-phase neural approach for symmetrical components estimation was developed. The instantaneous phase estimation block was added to deal with changing parameter in power grid by obtaining real time reference currents. The current controller based on a neural PI regulator was tested as well as with Bandless Hysteresis approach [13]. This allows generating phase-opposite the three-phase reference current on the grid to suppress harmonic and compensate reactive power.

Fig. 3 shows simulation results under a $20 \%$ unbalanced source voltage (Fig.3a) for mp-q and MSRF methods. The simulation parameters are given below: Source voltage $(\mathrm{Vsa}=55 \mathrm{~V}, \mathrm{Vsb}=40 \mathrm{~V}, \mathrm{Vsc}=81.6 \mathrm{~V}, \mathrm{f}=50 \mathrm{~Hz}$ ), Load (a rectifier and a R-L branch; $\mathrm{R}=20 \Omega, \mathrm{L}=12.5 \mathrm{mH}$ ). All type of non linear loads can be used. Results are shown for inductive loads because they are widely founded in industrial domain. The distorted load current is shown in Fig. 3b) while the source current after compensation corresponds to the waveform of Fig. 3c). This current reveals a THD up to $1.92 \%$ for a sampling time of $10 \mu \mathrm{s}$ which corresponds to the mp-q method. Fig. 4 presents waveforms under balanced load with a sudden decrease of load currents amplitude at time $0.08 \mathrm{~s}$. During simulations, we obtained the same results for the proposed distortion identification techniques. In addition, Table I shows the settling time and the source-side current THD after compensation. The fastest method is the MSRF with a settling time of $20 \mathrm{~ms}$ whereas the ITM method is the slowest one with a settling time of $45 \mathrm{~ms}$. Moreover, we can there notice that contrary to the other methods, ITM is adequate for single phase systems despite the lack of efficiency under unbalanced source voltage.

Hardware implementation was done on FPGA Stratix II target from the synthesis tool called Quartus ${ }^{\mathrm{TM}}$ II. Because of the limited quantity of logics resources available on the target, implementation optimization techniques were necessary for the algorithms. An efficient comparison of hardware resource consumption for different harmonic detection approaches takes also into account particular resources used for calculations. Embedded 9 bits-DSP blocks used to implement multipliers and Arithmetic Look-Up Tables (ALUT), basic cells used in the Quartus ${ }^{\circledR}$ II software for logic synthesis are one of them. As the multiplexing technique were applied to the neural $p-q$ to obtain a more area efficient structure called $\mathrm{mp}-\mathrm{q}$, the SRF and the Three Monophase methods have also been simplified to obtain respectively the MSRF and the ITM

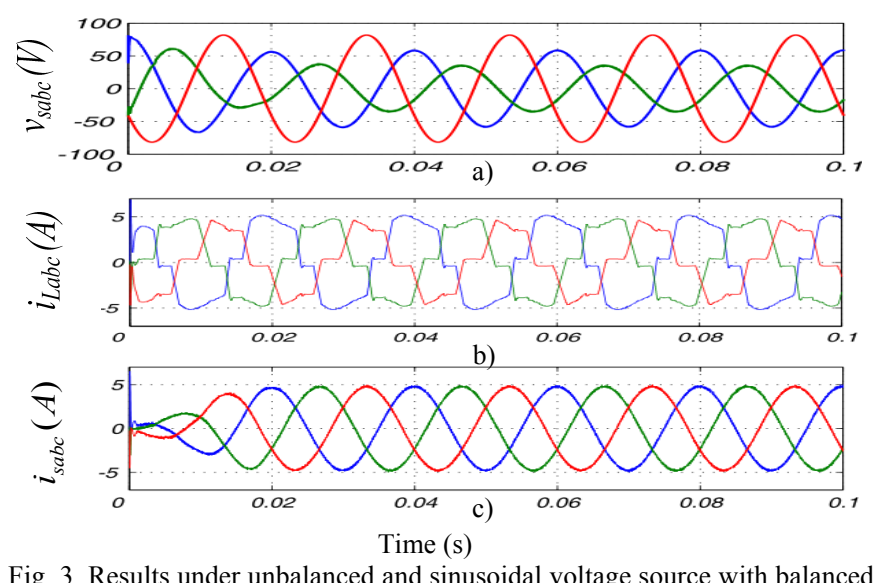

Fig. 3. Results under unbalanced and sinusoidal voltage source with balanced load for MSRF and mp-q methods: a) Unbalanced source voltage, b) Threephase distorted load current, c) Source current after compensation 

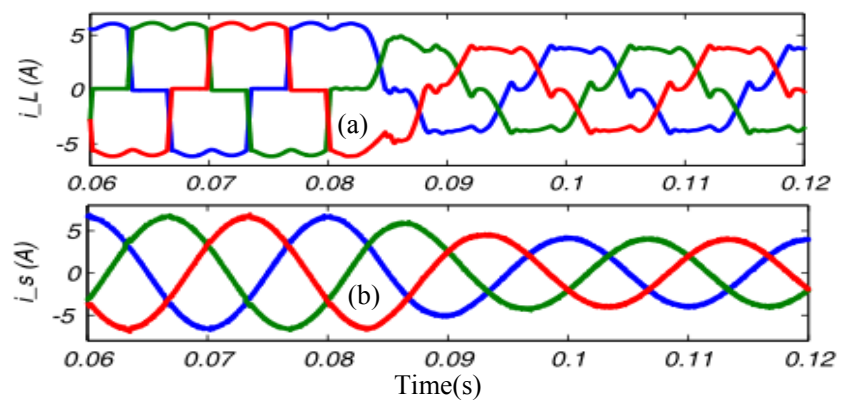

Fig. 4. Results under balanced load with a sudden change at $0.08 \mathrm{~s}$ for $\mathrm{mp}-\mathrm{q}$, MSRF and ITM methods : (a) Load current, (b) Source currents after harmonics suppression

techniques. Consequently, none of these identification methods exceeds $52 \%$ of the available resources on FPGA, as presented in Table II. The MSRF technique is the less consuming technique. It uses only $21.6 \%$ of FPGA calculation resources whereas the $\mathrm{mp}-\mathrm{q}$ formulation uses $45.3 \%$ and the ITM technique $52 \%$. This can be explained by the important number of Adalines used for harmonics detection, i.e. three for the ITM method instead of one for the others.

On the other hand, considering the medium scale FPGA used at a $100 \mathrm{MHz}$ frequency (corresponding to a period of 10ns), we can evaluate the latencies of the basic blocks. By adding them according to the dataflow, we raised latency of each functional module and thereafter the hardware execution time of the whole APF control unit architecture. As shown in Table III, the response time results for the identification methods are presented and compared each other. So, ITM appears to be the fastest technique with a response time of 0.6 $\mu \mathrm{s}$ when the mp-q is the slowest with a value of $1.34 \mu \mathrm{s}$. The reason is that the ITM technique is modeled without the symmetrical component extraction unit and the Concordia/Park transformation. In this way, obtained results in unbalanced conditions are not also good as for the others techniques. In all cases, the response times remain very short

TABLE I. RESULTS FROM THE HARMONICS DETECTION METHODS

\begin{tabular}{|lccc|}
\hline \hline $\begin{array}{l}\text { Harmonic } \\
\text { detection }\end{array}$ & $\begin{array}{c}\text { Settling } \\
\text { time }\end{array}$ & $\begin{array}{c}\text { Adequate for } \\
\text { single phase }\end{array}$ & $\begin{array}{c}\text { Obtained Source } \\
\text { current THD }\end{array}$ \\
\hline$m p-q$ & $27 \mathrm{~ms}$ & no & $1.92 \%$ \\
$I T M$ & $45 \mathrm{~ms}$ & yes & $1.75 \%$ \\
$M S R F$ & $20 \mathrm{~ms}$ & no & $1.78 \%$ \\
\hline
\end{tabular}

TABle II: EVAluation of Resource CONSUmption FOR THE IDENTIFICATION METHODS

\begin{tabular}{|l|r|c|c|c|}
\hline \hline \multirow{2}{*}{ Resources } & \multirow{2}{*}{ Available } & \multicolumn{3}{|c|}{ FPGA resources in \% } \\
\cline { 3 - 5 } & & $M S R F$ & $I T M$ & $M P-Q$ \\
\hline ALUT & 143,520 & $4 \%$ & $32 \%$ & $17 \%$ \\
Memory (RAM) & $9,383,040$ & 4 & 24 & 8 \\
9-bits DSP & 768 & 57 & 100 & 99 \\
Register blocks & 147,818 & 0.6 & 2.6 & 0.50 \\
Pins & 783 & 11 & 11 & 11 \\
PLL & 12 & 8 & 8 & 8 \\
\hline $\begin{array}{l}\text { Average }(R A M+D S P+A L U T) \\
\text { consumption }\end{array}$ & $21.6 \%$ & $52 \%$ & $41.33 \%$ \\
\hline
\end{tabular}

TABLE III. RESPONSE TIME OF THE APF CONTROL UNIT ARCHITECTURE EVALUATION

\begin{tabular}{|l|l|l|l|}
\hline \hline \multirow{2}{*}{ Module } & \multicolumn{3}{|c|}{ Execution time $(\mu \mathrm{s})$} \\
\cline { 2 - 4 } & SRFM & ITM & $M P-Q$ \\
\hline phase detection & 0.27 & 0.27 & 0.27 \\
symmetrical component & - & - & 0.49 \\
concordia/Park transform & 0,16 & - & 0.16 \\
dc components & 0,12 & 0,12 & 0.1 \\
Inverse Concordia/park transform & 0,14 & - & 0.25 \\
other multipliers & & 0.14 & \\
current control & 0.07 & 0.07 & 0.07 \\
\hline Response time & $\mathbf{0 . 7 6}$ & $\mathbf{0 . 6}$ & $\mathbf{1 . 3 4}$ \\
\hline \hline
\end{tabular}

and this confirms choice of a FPGA target especially in implementing neural based architectures.

\section{EXPERIMENTAL RESULTS}

As can be seen in Fig. 5, we used an experimental platform including a three-phase APF, a three-phase power supply, a nonlinear load, a computer, and the control unit built from the FPGA board associated with an analog inputs card. The power stage consists of a Semikron SKM 50 GB 123D inverter with insulated-gate bipolar transistor (IGBT) modules. The split capacitor of the DC bus is $4400 \mu \mathrm{F}$ and R$\mathrm{L}$ branches are applied to suppress the filter current ripple. Such a design can operate at a line-to-neutral voltage of $230 \mathrm{~V}$ rms and 10-kVA power.

APF control unit implementation with a unique FPGA is possible without association with a DSP as it is almost always the case. An auxiliary card is used for assuring acquisition and A/D conversion of the current and voltage signals for the FPGA, and also to amplify the gating signals from $0-3.3 \mathrm{~V}$ to $0-15 \mathrm{~V}$ needed by IGBTs. ADCs are simultaneously controlled at a sampling frequency of $5 \mathrm{MHz}$ from the FPGA. The nonlinear load is made up of a diode rectifier and a R-L branch in the DC side. Due to real-time constraints, the switching frequency of the IGBT has been set to $12.5 \mathrm{kHz}$ which is adequate for this application. The system parameters are summarized in Table IV where $V S$ is the line source voltage, $f$ is the system frequency, $V_{D C}$ is the voltage of the DC bus capacitor $C_{D C}, R_{f}$ and $L_{f}$ are respectively the filter resistance and inductance, $f_{s w}$ is the switching frequency, $R_{L}$ and $L_{L}$ are respectively the load resistance and inductance.

First, experimental study is made for ITM and MSRF harmonics detection methods. Fig. 6 shows the waveforms for balanced and nonlinear load. These waveforms are obtained after reducing the $230 \mathrm{~V}$ source voltage by a transformer. The source voltage, the load current, the compensating current and

TABLE IV. SYSTEM PARAMETERS

\begin{tabular}{|cc|}
\hline \hline Power source & Values \\
\hline$V s, f$ & $40 \mathrm{~V}, 50 \mathrm{~Hz}$ \\
\hline \hline Active power filter & Values \\
\hline$V_{D C}, C_{D C}$ & $85 \mathrm{~V}, 4400 \mu \mathrm{F}$ \\
$R_{f,} L_{f}$ & $5 \Omega, 5.8 \mathrm{mH}$ \\
$f_{s w}$ & $12.5 \mathrm{Khz}$ \\
\hline \hline Non linear load & Values \\
\hline$R_{L,} L_{L}$ & $20 \Omega, 15.4 \mathrm{mH}$ \\
\hline \hline
\end{tabular}




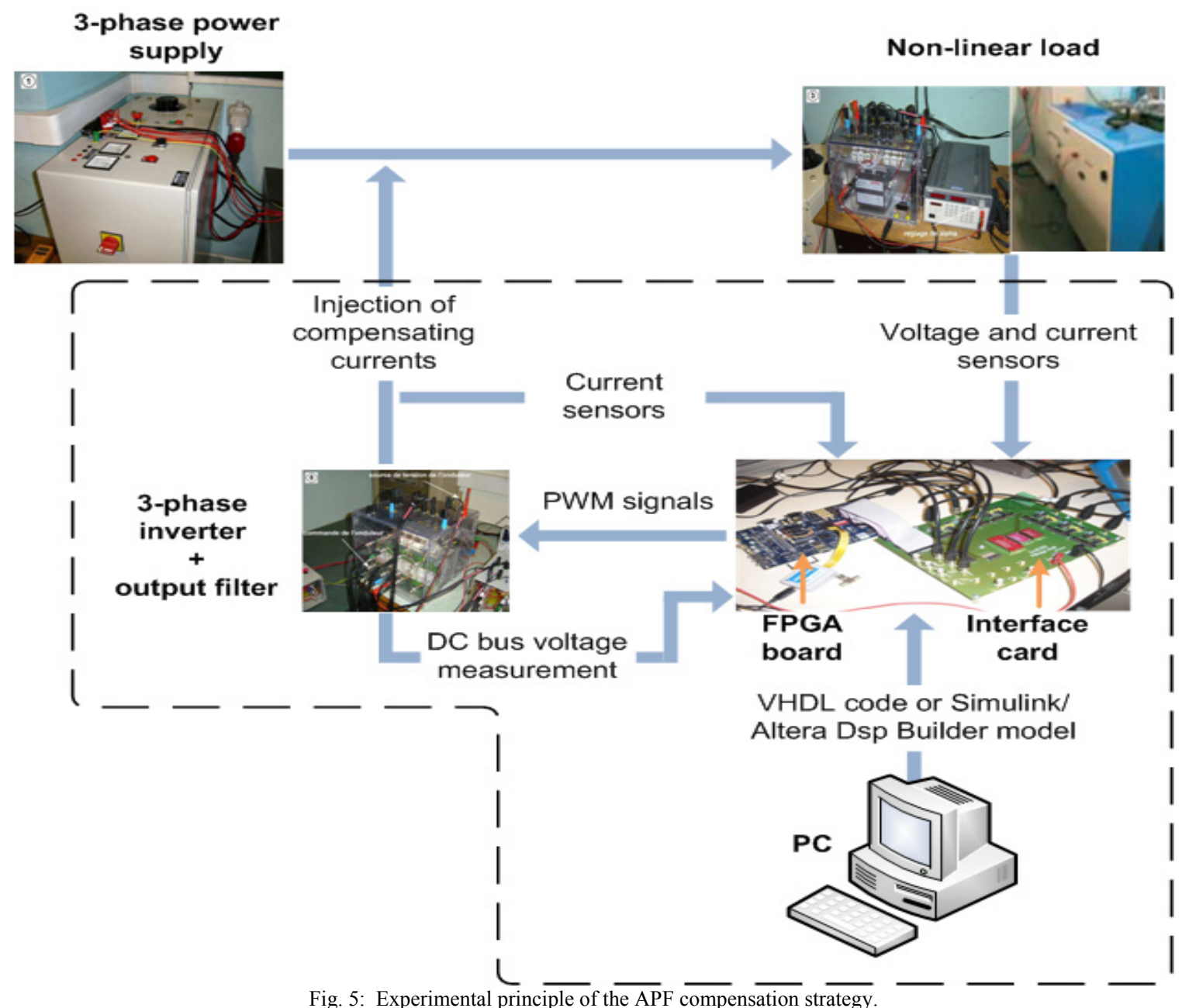

the source-side current after compensation are shown in topto-bottom order. Harmonics spectra of the compensated source current and load current are represented in Fig. 7. We can see that all harmonic components are cancelled to obtain good sinusoidal source currents in phase with the voltage signal so as to correct the power factor of the supply current near to unity. It can also be seen from Fig. 8 that the designed adaptive shunt APF can adapt to a change in the non-linear

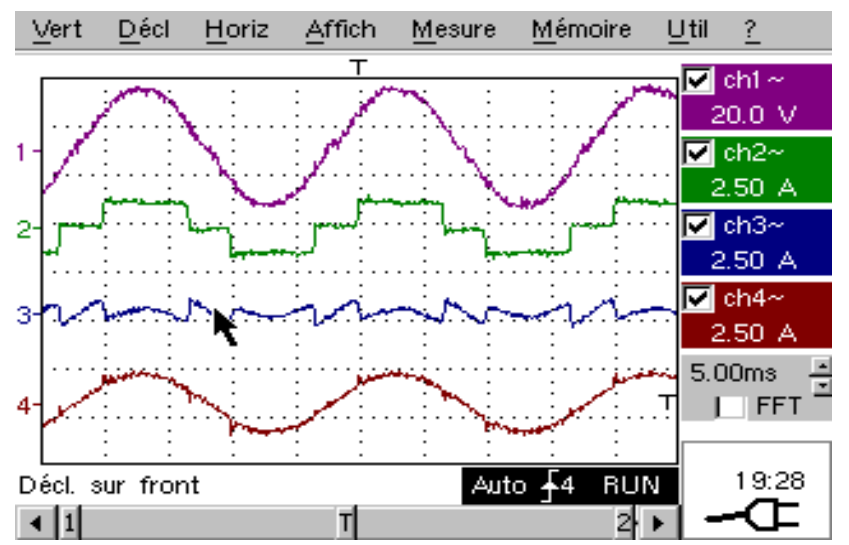

Fig.6. Experimental results for ITM and MSRF methods: 1) source voltage 2) load current 3 ) reference current, 4) source-side current after compensation load current. When non linear load values change from $\left(\mathrm{R}_{\mathrm{L}}=20 \Omega, \mathrm{L}_{\mathrm{L}}=15.4 \mathrm{mH}\right)$ to $\left(\mathrm{R}_{\mathrm{L}}=6.55 \Omega, \mathrm{L}_{\mathrm{L}}=20 \mathrm{mH}\right)$, we still obtain good filtering performance. The reference current waveforms extracted from the load current are quite similar for the different methods especially in balanced conditions (mp-q, MSRF and ITM). Table V shows the THD of the source-side current after the APF compensation for an initial THD of $30 \%$. The best result is obtained for the mp-q

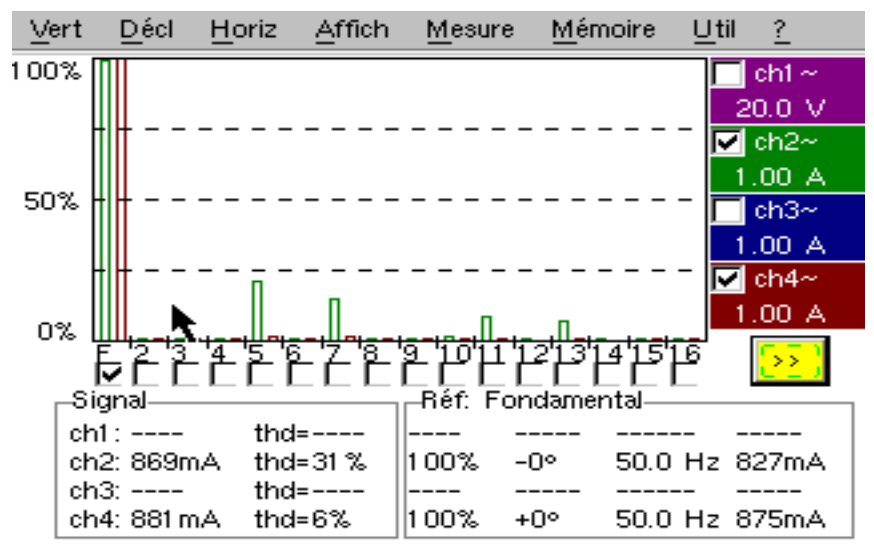

Fig.7. Spectral decomposition of the source-side current before and after compensation 
method with a THD of 3.3\%. All the THD values, even the one for the ITM method can be significantly reduced by choosing an APF output filter of third order to fit the source current inside the distortion bounds set at $5 \%$ by the standards. The results have confirmed very good performance in terms of waveform quality and response time.

\section{CONCLUSION}

Experimental results of distortions compensation through the APF have been presented and confirm those obtained after simulation in various utility conditions. The APF control unit was implemented on a unique target, i.e a FPGA Stratix II available on a development board which worked in association with an analog inputs card. A comparative study was presented after simulation and Hardware implementation of three adaptive distortions identification techniques based on neural networks. Whatever the harmonic detection method used, we can argue that it is possible to obtain the compensated source current THD value which agrees with IEC standards. In addition to the APF performances, even the most consuming ITM method presents interesting perspectives in terms of FPGA material resources reduction by consuming less than $52 \%$ of FPGA calculation resources.

So, with appropriate design, mapping the algorithm with adequate system performance is reachable despite the lack of resources. Despite MSRF distortion identification has the fastest response in simulation, i.e., a settling time of $20 \mathrm{~ms}$, the smallest resource utilization ratio, i.e., $21.6 \%$, and practically the smallest execution time after hardware implementation for three-phase compensation, the mp-q technique appears as one of the best harmonics identification strategy for its filtering aptitudes with an experimental source-side current THD of $3.3 \%$ after compensation. Moreover, its results are still interesting under unbalanced conditions.

Although other methods for the control of APF are widely known, the hardware implementation of the whole APF control unit with only neural networks is an interesting issue.
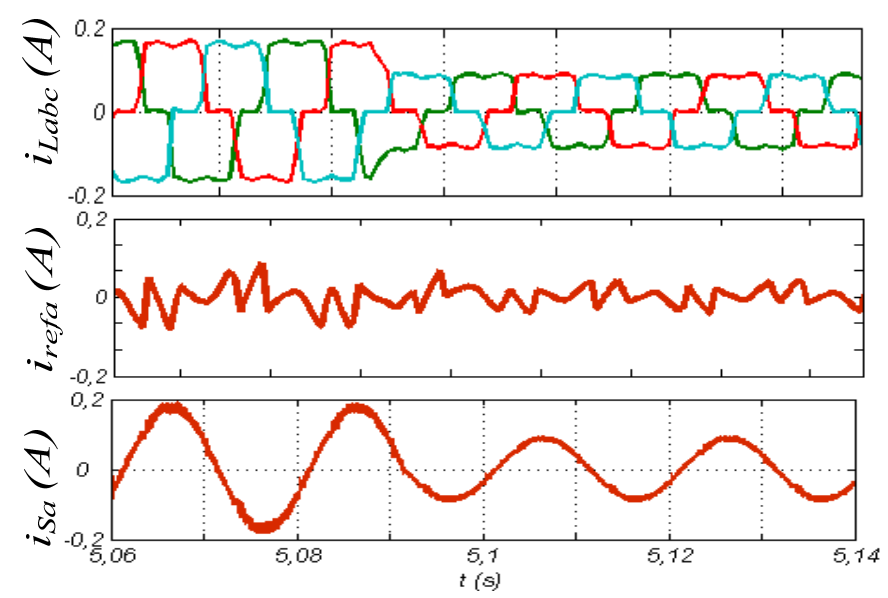

Fig. 8. Experimental results for the mp-q method - 1) three-phase load current 2) Single phase reference current, 3) source-side current after compensation
TABLE V. THD OF THE GRID CURRENT UNDER SINUSOIDAL VOLTAGE CONDITIONS AFTER THE CONNECTION OF THE APF

\begin{tabular}{lc}
\hline \hline Harmonics & THD after \\
extraction method & compensation \\
\hline$m p-q$ & $3.3 \%$ \\
$I T M$ & $7 \%$ \\
$M S R F$ & $6 \%$ \\
\hline
\end{tabular}

The use of FPGA target for such applications certainly improves the global performances due to its aptitudes for parallel processing.

\section{REFERENCES}

[1] C. H. Da Silva, R. R. Pereira, L. E. B. Da Silva, G. Lambert-Torres and B. K. Bose, Improving the dynamic response of shunt active power filter using modified Synchronous Reference Frame PLL, in proc. of 34th Conference of IEEE Industrial Electronics (IECON), 2008 , pp 790 -795 .

[2] H. Akagi, Y. Kanazawa, and A. Nabae, "Instantaneous reactive power compensators comprising switching devices without energy storage components," IEEE Trans. Ind. Appl., Vol. IA-20, No. 3, pp. 625-630, May/Jun. 1984

[3] R. S. Herrera, P. Salmerón, and H. Kim, "Instantaneous reactive power theory applied to active power filter compensation: Different approaches, assessment, and experimental results," IEEE Trans. Ind. Electron., Vol. 55, No. 1, pp. 184-196, Jan. 2008.

[4] S. R. N. Dzondé, C-H. Kom, H. Berviller, J-P. Blondé, D. Flieller, M. Kom, and F. Braun, Neural Harmonic Detection approaches for FPGA Area efficient Implementation, European Physical Journal - Applied Physics, 56, 30901 (2011)

[5] S. R. N. Dzondé, H. Berviller, J-P. Blonde, F Braun, C H. Kom, and M. Kom, "FPGA Implementation of Harmonic Currents detection methods using Neural Networks," in proc. of $13^{\text {th }}$ European Conference on Power Electronics and Applications (EPE'09), Sept. 8-10 ${ }^{\text {th }}$, Barcelona, Spain, 2009, CDROM.

[6] N. K. Nguyen, D. Flieller, P. Wira, and D. Ould Abdeslam, "Neural networks for phase and symmetrical components estimation in power systems," 35th Annual Conference of the IEEE Industrial Electronics Society (IECON09), Porto, Portugal, November 3-5, 2009, CD-ROM.

[7] D. Flieller, D. Ould Abdeslam, P. Wira, and J. Mercklé, Distortions Identification and Compensation Based on Artificial Neural Networks Using Symmetrical Components of the Voltages and the Currents, Electric Power Systems Research, Vol. 79, No. 7, pp. 1145-1154, 2009.

[8] S. R. N. Dzondé, N. K. Nguyen, C-H. Kom, H. Berviller, J-P. Blondé, M. Kom, and F. Braun, FPGA resources reduction by a multiplexing technique applied on ANN-based harmonics extraction algorithms, Journal of Energy and Power Engineering 6 (2012) 469-477, USA

[9] S. R. Dzondé, N. K. Nguyen, H. Berviller, C.-H. Kom, J.-P. Blondé, M. Kom, and F. Braun, FPGA resources reduction with multiplexing technique for implementation of ANN-based harmonics extraction by mp-q method, in proc. of the 36th Annual Conference of the IEEE Industrial Electronics Society (IECON'10), Nov. 7-10th, 2010, AZ, USA, pp. 2037-2042

[10] M. Krips, T. Lammert, and A. Kummert, FPGA implementation of a neural network for a real-time hand tracking system. in proc. of the $1 \mathrm{st}$ IEEE Int. Workshop on Electronic Design, Test and Applications (DELTA), Christchurch, New Zealand, 29-31 Jan. 2002, pp. 313-317.

[11] A. R. Omondi and J. C. Rajapakse. Fpga Implementations of Neural Networks. Springer, 2006.

[12] B. Widrow and E. Walach, Adaptive inverse control. Information and System Science Series. Prentice Hall Press, Upper Saddle River, 1996

[13] M. A. M. Radzi and N. A. Rahim, "Neural Network and Bandless Hysteresis Approach to Control Switched Capacitor Active Power Filter for Reduction of harmonics," IEEE Transactions On Industrial Electronics, Vol. 56, No. 5, pp. 1477-1484, May 2009. 